\title{
Low-rise structures in reinforced concrete: approximation of material nonlinearity for global stability analysis
}

\section{Estruturas de pequeno porte em concreto armado: consideração aproximada da não-linearidade física para análise da estabilidade global}
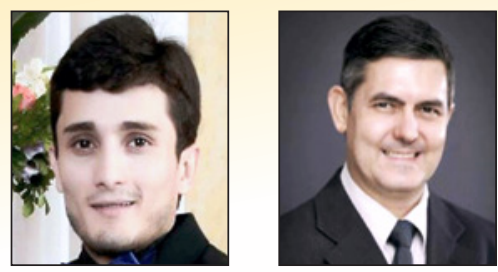

\author{
L. MOREIRA \\ moreiralm19@gmail.com \\ C. H. MARTINS \\ chmartins2007@gmail.com
}

\begin{abstract}
In the analysis of the second-order global effects, the material nonlinearity (NLF) can be considered in an approximate way, defining for the set of each structural element a mean flexural stiffness. However, there is less research concerning low-rise buildings in the analysis of global stability in contrast to high buildings, because these have a greater sensitivity to this phenomenon and they are more studied. In this way, the paper objective is to determine the flexural stiffness values, of beams and columns, for buildings with less than four floors, to approximate consideration of the NLF in the global analysis. The idealized examples to buildings with 1, 2 and 3 floors, being simulated through the software CAD/TQS and an analysis model based in an iterative process. The simulations results defined the stiffness values of the set of beams and columns in each example, followed by a statistical analysis to define general values of application in the buildings. Finally, a proposal is suggested of stiffness reduction coefficients for beams and columns to be adopted in the approximation the $\operatorname{NLF}\left(\mathrm{El}_{\mathrm{sec}}=\alpha_{\mathrm{v} / \mathrm{p}} \cdot \mathrm{E}_{\mathrm{ci}} \mathrm{I}_{\mathrm{c}}\right)$, as follows: buildings with 1 floor $\left(\alpha_{v}=0,17\right.$ and $\left.\alpha_{p}=0,66\right)$, buildings with 2 floors $\left(\alpha_{v}=0,15\right.$ and $\left.\alpha_{v}=0,71\right)$ and buildings with 3 floors $\left(\alpha_{v}=0,14\right.$ and $\left.\alpha_{v}=0,72\right)$. The results obtained can be used for the analysis of low-rise structures to consider the second order global effects with more safely.
\end{abstract}

Keywords: second order effects, global analysis, stiffness of structural elements.

\section{Resumo}

$\mathrm{Na}$ análise dos efeitos globais de segunda ordem, a não-linearidade física (NLF) pode ser considerada de forma aproximada, definindo-se para o conjunto de cada elemento estrutural, uma rigidez secante à flexão. No entanto, encontram-se menos pesquisas referentes a edifícios baixos na análise da estabilidade global em contraste com os edifícios altos, pois estes possuem uma maior sensibilidade a esse fenômeno e, consequentemente, são objeto de maior estudo. Desta forma, o objetivo deste trabalho é determinar os valores de rigidez à flexão, de vigas e pilares, para edificações com menos de quatro pavimentos, de modo a considerar a NLF de forma aproximada na análise global. Os exemplos idealizados são referentes a edificações com 1, 2 e 3 pavimentos, sendo simulados através do software CAD/TQS e por meio de um modelo de análise baseado em um processo iterativo. Os resultados das simulações definiram os valores da rigidez do conjunto de vigas e de pilares em cada exemplo, prosseguindo-se a uma análise estatística com o intuito de se definir valores gerais de aplicação nas edificações. Por fim, apresenta-se uma proposta de coeficientes redutores de rigidez para vigas e pilares a serem adotados na consideração da NLF de forma aproximada $\left(E I_{s e c}=\alpha \cdot E_{c i} I_{c}\right)$, conforme a seguir: edifícios com 1 pavimento $\left(\alpha_{v}=0,17\right.$ e $\left.\alpha=0,66\right)$, edifícios com 2 pavimentos $\left(\alpha_{v}=0,15\right.$ e $\left.\alpha_{v}=0,71\right)$ e edifícios com 3 pavimentos $\left(\alpha_{v}=0,14\right.$ e $\left.\alpha_{v}=0,72\right)$. Os resultados obtidos podem ser utilizados para a análise de estruturas de pequeno porte de modo a se considerar os efeitos globais de segunda ordem de forma mais segura.

Palavras-chave: efeitos de segunda ordem, análise global, rigidez dos elementos estruturais. 


\section{Introduction}

Basically, a global stability analysis evaluates the global secondorder effects on buildings, considering the material nonlinearity of the included materials and the geometric nonlinearity that result from the structure in its deformed state. However, at that stage, the structural elements are not yet scaled out, and consequently, there are no details on the armor. As a result, the global stability analysis is characterized as a preliminary step before scaling structures, and thus, an approximate evaluation of the material nonlinearity is conducted. The material nonlinearity can be approximately considered, by establishing the secant stiffness of bending for each structural element. However, there have been very few studies on low rise buildings in the analysis of global stability compared to tall buildings because these have a higher sensitivity to this phenomenon, and consequently, are subject to more studies.

This idea is corroborated by the fact that the ABNT NBR 6118:2014 in its item 15.7.3 proposes approximate stiffness values for beams, columns and slabs in buildings with at least four floors.

According to IBRACON (2015), the use of these stiffness values proposed by the standards organization for smaller buildings may lead to results detrimental to the safety of the structures as these values are usually smaller.

However, setting the stiffness for the entire set of beams and columns in low rise buildings is essential but highly complex at the same time. In fact, each building has unique features that, in turn, affect the setting of the secant stiffness of the entire set of its structural elements. Thus, statistical analysis becomes an important tool for the integration of the specificities of each building.

Khuntia and Ghosh (2004a) obtained values of effective bending stiffness $\left(\mathrm{EI}_{\mathrm{ef}}\right)$ for beams and columns through an analytical approach. They conducted a parametric study where the analysis of beams and columns was conducted separately to investigate the dependency that exists between bending stiffness and other relevant parameters. According to the results obtained, they proposed an equation for the calculation of $\mathrm{EI}_{\mathrm{ef}}$ for columns, by equation 1 .

$\mathrm{EI}_{\mathrm{ef}}=\mathrm{E}_{\mathrm{c}} \mathrm{I}_{\mathrm{g}} \cdot\left(0,80+25 \cdot \rho_{\mathrm{g}}\right) \cdot\left(1-\frac{\mathrm{e}}{\mathrm{h}}-0,5 \cdot \frac{\mathrm{P}_{\mathrm{u}}}{\mathrm{P}_{\mathrm{o}}}\right)$

where:

$\mathrm{El}_{\mathrm{ef}}$ : effective bending stiffness;

$E_{c g} I_{g}$ : bending stiffness of the gross section;

$\rho_{\mathrm{g}}$ : longitudinal armor rate;

$\mathrm{e} / \mathrm{h}$ : relative eccentricity;

$\rho_{\mathrm{u}}$ : requested normal force of calculation;

$\rho_{0}$ : resistant normal force of calculation.

For beams, they proposed expressions for the following situations:

I. For rectangular beams with $\mathrm{f}_{\mathrm{ck}} \leq 41,4 \mathrm{MPa}$, the $\mathrm{EI}_{\mathrm{ef}}$ can be calculated by equation 2 or equation 3 that consider the inertia moment of the cracked section.

$\mathrm{EI}_{\mathrm{ef}}=\mathrm{E}_{\mathrm{c}} \mathrm{I}_{\mathrm{g}} \cdot\left(0,10+25 \cdot \rho_{\mathrm{g}}\right) \cdot\left(1,2-0,2 \cdot \frac{\mathrm{b}}{\mathrm{d}}\right) \leq 0,6 \cdot \mathrm{E}_{\mathrm{c}} \mathrm{I}_{\mathrm{g}}$

$I_{c r}=\frac{b \cdot c^{3}}{3}+n \cdot A_{s} \cdot(d-c)^{2}$ where

$\mathrm{El}_{\text {ef }}$ : effective bending stiffness;

$E_{c} I_{g}$ : bending stiffness of the gross section;

$\rho_{\mathrm{g}}$ : longitudinal armor rate;

$b$ : width of the beam;

$d$ : clear height of the section;

$c:$ depth of the neutral line;

$\mathrm{n}$ : relationship between the elasticity modules of steel and concrete;

$A_{s}$ : positive armature steel area.

II. For rectangular beams with $\mathrm{f}_{\mathrm{ck}}>41,4 M P a$, the $\mathrm{EI}_{\mathrm{ef}}$ can be calculated by equation 4 .

$\mathrm{EI}_{\mathrm{ef}}=\mathrm{E}_{\mathrm{c}} \mathrm{I}_{\mathrm{g}} \cdot\left(0,10+25 \cdot \rho_{\mathrm{g}}\right) \cdot\left(1,2-0,2 \cdot \frac{\mathrm{b}}{\mathrm{d}}\right)$.

$\left[1,15-\left(4 \cdot 10^{-5}\right) \cdot \mathrm{f}_{\mathrm{c}}^{\prime}\right] \leq 0,6 \cdot \mathrm{E}_{\mathrm{c}} \mathrm{I}_{\mathrm{g}}$

where:

$\mathrm{El}_{\mathrm{ef}}$ : effective bending stiffness;

$E_{c} I_{g}$ : bending stiffness of the gross section;

$\rho_{\mathrm{g}}$ : longitudinal armor rate;

$\mathrm{b}$ : width of the beam;

$d$ : clear height of the section;

$f_{c}^{\prime}$ : concrete's compressive strength.

III. For beams with section $\mathrm{T}$ and compressed table, the $\mathrm{EI}_{\mathrm{ef}}$ can be calculated by equation 5 .

$\frac{\mathrm{EI}_{\text {efT }}}{\mathrm{EI}_{\mathrm{ef}}}=\left(1,0+2,0 \cdot \frac{\mathrm{t}_{\mathrm{f}}}{\mathrm{h}}\right) \leq 1,4$

where

$\mathrm{El}_{\text {eft }}$ : effective bending stiffness for beams with T-section;

$\mathrm{El}_{\text {ef }}$ : effective bending stiffness for rectangular beams;

$t_{f}$ : width of the table;

$\mathrm{h}$ : height of the section.

Based on the equations, Khuntia and Ghosh (2004a) suggested a methodology for considering the values of $\mathrm{EI}_{\mathrm{ef}}$ for portico beams and columns, with emphasis on slender columns:

1. In the analysis of porticos, for the consideration of the global effects of first and second-order, values of $\mathrm{El}_{\mathrm{ef}}=0,35 \cdot \mathrm{E}_{\mathrm{c}} \mathrm{I}_{\mathrm{g}}$ for beams and $\mathrm{El}_{\mathrm{ef}}=0,7 \cdot \mathrm{E}_{\mathrm{c}} \mathrm{I}_{\mathrm{g}}$ for columns can be assumed.

2. At the end of this first analysis, the values of El_ef for the beams and columns were recalculated following equations 1 and 2 .

If the values obtained are greater than $15 \%$ of the initial values considered, it is recommended to perform a new analysis using the values obtained by the equations. Otherwise, performing a new analysis is not required.

Khuntia and Ghosh (2004b) validated the analytic approach designed in Khuntia and Ghosh (2004a) through experimental analysis.

Martins (2008) analyzed reinforced concrete beams, bi-supported and bi-embedded, with different rates of longitudinal armor and distributed loads, using a finite element formulation, considering integrated concrete between cracks as a contributing factor (tension stiffening) and $\mathrm{M}-1 / \mathrm{r}$ diagrams to evaluate the $\mathrm{EI}_{\mathrm{ef}}$ of the beams in the two above-mentioned binding situations. For the bi-supported beams, the values obtained were $0,41 \cdot \mathrm{E}_{\mathrm{cic}} \leq \mathrm{El}_{\mathrm{ef}} \leq$ $0,54 \cdot \mathrm{E}_{\mathrm{ci}} \mathrm{I}_{\mathrm{c}}$. For the bi-embedded beams, the values obtained were $0,57 \cdot \mathrm{E}_{\mathrm{cic}} \mathrm{I}_{\mathrm{c}} \leq \mathrm{El}_{\mathrm{ef}} \leq 0,64 \cdot \mathrm{E}_{\mathrm{ci}} \mathrm{I}_{\mathrm{c}}$, where $\mathrm{E}_{\mathrm{ci}}$ is the concrete's initial tangent modulus of elasticity and $I_{c}$ is the moment of inertia of the gross section of the beams. As the bending of the beams in 
reinforced concrete buildings should be an intermediate situation in relation to those analyzed, the approximate $\mathrm{EI}_{\text {ef }}$ for the beams should be considered as $0,54 \cdot E_{c i c} I_{c}$ in verifications of the ultimate state limit design. However, according to the results obtained, Martins emphasized that the $\mathrm{EI}_{\text {ef }}$ should be differentiated for the beams with equal and different lower and upper armor.

The $\mathrm{ACl}$ 318:2014 suggests the use of equations 1 and 2 proposed by Khuntia and Ghosh (2004a) for the calculation of $\mathrm{EI}_{\mathrm{ef}}$ for columns and beams, respectively. However, for the columns, the limits of $0,35 \cdot E_{c g} \leq E_{e f} \leq 0,875 \cdot E_{c} I_{g}$ are set. Moreover, for the beams, the limits are $0,25 \cdot E_{c} I_{g} \leq E_{e f} \leq 0,50 \cdot E_{c} I_{g}$. The final values of $\mathrm{EI}_{\mathrm{ef}}$ should also be multiplied by the reduction factor $\varnothing_{\mathrm{k}}=0,875$. According to Franco (1995), this reduction only makes sense for the general formulation of the American standard.

Bueno (2014) determined stiffness values to be used for beams $\left(E_{s e c}=\alpha_{v} \cdot E_{c i c} I_{c}\right)$ and columns $\left(E_{s e c}=\alpha_{p} \cdot E_{c i c} I_{c}\right)$ in buildings with less than four floors, to consider the material nonlinearity, in an approximate manner, in the evaluation of global stability. To obtain these values, a number of examples were designed and their respective analyses were conducted using the CAD/TQS software, version 16.9.79, considering the specifications of the ABNT NBR 6118:2007. Finally, the following values for the stiffness coefficients were suggested: buildings with 1 floor $\left(\alpha_{v}=0,20\right.$ and $\left.\alpha_{p}=0,60\right)$, buildings with 2 floors $\left(\alpha_{v}=0,30\right.$ and $\left.\alpha_{p}=0,60\right)$, buildings with 3 floors $\left(\alpha_{v}=0,30\right.$ and $\left.\alpha_{p}=0,70\right)$ and buildings with 4 to 10 floors $\left(\alpha_{v}=0,40\right.$ and $\left.\alpha_{p}=0,80\right)$.

As defined earlier, in the global analysis, the geometric nonlinearity is associated with the changes that occur in the geometry of the structure as a whole and there are established methods to evaluate it (e. g., coefficient $\gamma_{z}, P-\Delta$ analysis, the method of the geometric stiffness matrix). However, the consideration of the geometric nonlinearity essentially depends on a good evaluation of the deformed structure, i.e., the correct consideration of the material nonlinearity.

\subsection{Objective}

To determine the values of bending stiffness of beams and columns, for buildings with less than four floors; to enable the evaluation of material nonlinearity, in an approximate manner, for the global stability analysis of low rise buildings.

\subsection{Justification}

The ABNT NBR 6118:2014 suggests the use of the instability parameter $\alpha$ and/or the coefficient $\gamma_{z}$ for the evaluation of global second-order effects.

Unlike the instability parameter $\alpha$ that incorporates the values of bending stiffness of the cross-linked structure in its formulation, it becomes necessary to consider the material nonlinearity with stiffness reducing values of the structural elements suggested by the standard in item 15.7.3 in the calculation of the coefficient $\gamma_{z}$. However, these values are for buildings with at least four floors, thus preventing the use of the coefficient $\gamma_{z}$ in smaller buildings.

Because the instability parameter $\alpha$ does not have this limitation, it can be used to assess the overall stability instead of the coefficient $\gamma_{\mathrm{z}}$. However, the instability parameter a does not allow the calculation of the second-order global effects, unlike the coefficient $\gamma_{z}$.
Therefore, the determination of the stiffness values of structural elements for buildings with less than four floors makes it possible to use the coefficient $\gamma_{z}$ for the evaluation of global stability and calculation of the second-order global effects (when needed) for buildings of this size.

In relation to the calculation of the second-order global effects, the values of bending stiffness can also be used in considerably complex methods for the evaluation of geometric nonlinearity, such as the P- $\Delta$ analysis and the geometric stiffness matrix method.

\section{Materials and numerical simulations}

In this study, we attempted to define an analysis method different from that employed by Bueno (2014), to expand the investigation of the approximate material nonlinearity into the evaluation of global stability. According the objective, it is required to set the stiffness values of beams $\left(E I_{s e c}=\alpha_{v} \cdot E_{c i c} I_{c}\right)$ and columns $\left(E_{s e c}=\alpha_{p} \cdot E_{c i c} I_{c}\right)$ for buildings with less than four floors.

As such, we used the CAD/TQS software, version 18.11.53, made available by the Department of Civil Engineering of the State University of Maringa, because it fulfills the requirements of the ABNT NBR 6118:2014 and includes advanced and automated analysis methods.

\subsection{Characterization of the studied examples}

The examples studied are relative to buildings with one, two, and three floors. The following are some fixed characteristics adopted in all examples:

For the classification of environmental aggressiveness, we selected class II;

- The presence of masonry walls was considered over all the beams on all floors (on the coverage floors, the height of the walls was of $1 \mathrm{~m}$ ), composed of concrete blocks 14 and $19 \mathrm{~cm}$ wide for beams 15 and $20 \mathrm{~cm}$ wide, respectively;

- The slabs of the standard pavement are $12 \mathrm{~cm}$ thick with 2.0 and $3.0 \mathrm{kN} / \mathrm{m}^{2}$ permanent and accidental load, respectively.

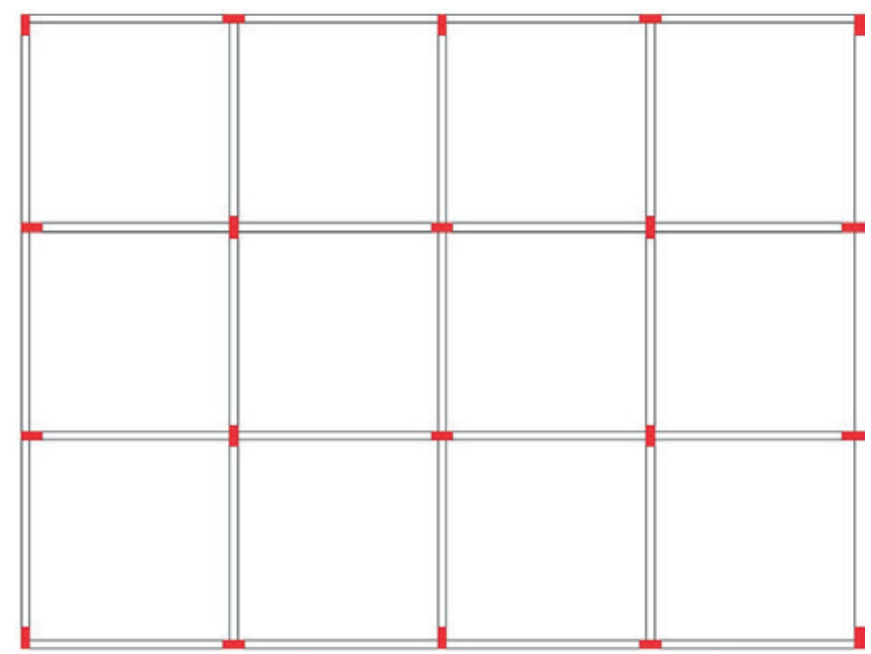

Figure 1

Plant of structural shapes $T_{1}$

Source: Author 
Table 1

Types of structural configurations

\begin{tabular}{|c|c|c|c|c|}
\hline Nomenclature & $\begin{array}{c}\text { Beams } \\
(\mathbf{c m} \times \mathbf{~ c m})\end{array}$ & $\begin{array}{c}\text { Columns } \\
(\mathbf{c m} \times \mathbf{~ c m})\end{array}$ & $\begin{array}{c}\text { Height of floor to floor } \\
(\mathbf{m})\end{array}$ & $\begin{array}{c}\text { Length of beams } \\
(\mathrm{m})\end{array}$ \\
\hline E & $20 \times 50$ & $20 \times 50$ & 4 & 5 \\
\hline F & $20 \times 40$ & $20 \times 40$ & 3 & 4 \\
\hline$G$ & $20 \times 40$ & $20 \times 40$ & 4 & 5 \\
\hline$H$ & $15 \times 40$ & $15 \times 40$ & 3 & 4 \\
\hline I & $20 \times 40$ & $20 \times 35$ & 4 & 4 \\
\hline J & $15 \times 30$ & $15 \times 25$ & 3 & \\
\hline \multicolumn{4}{|l}{} \\
\hline Source: Author
\end{tabular}

While the slabs of the coverage pavement are $12 \mathrm{~cm}$ thick with $3.0 \mathrm{ken} / \mathrm{m}^{2}$ of permanent and incidental load;

- The action of the wind and geometric imperfections in four directions $\left(0^{\circ}, 90^{\circ}, 180^{\circ}\right.$ and $\left.270^{\circ}\right)$ were also taken into consideration, resulting in 83 combinations of actions for analysis.

For the analysis of the size of each building 16 examples were designed, based on different types of structural shapes, structural configurations, basic wind speeds and characteristic strength of concrete. These parameters are presented in Figures 1 and 2 and Tables 1, 2 and 3.

It should be noted that, from the structural configurations listed in Table 1, only classifications $E$ and $F$ are used in the examples with three floors. Classifications $\mathrm{G}$ and $\mathrm{H}$ are only used in the examples with two floors. Classifications I and $\mathrm{J}$ are only used in the examples with one floor. This differentiation was used to es-

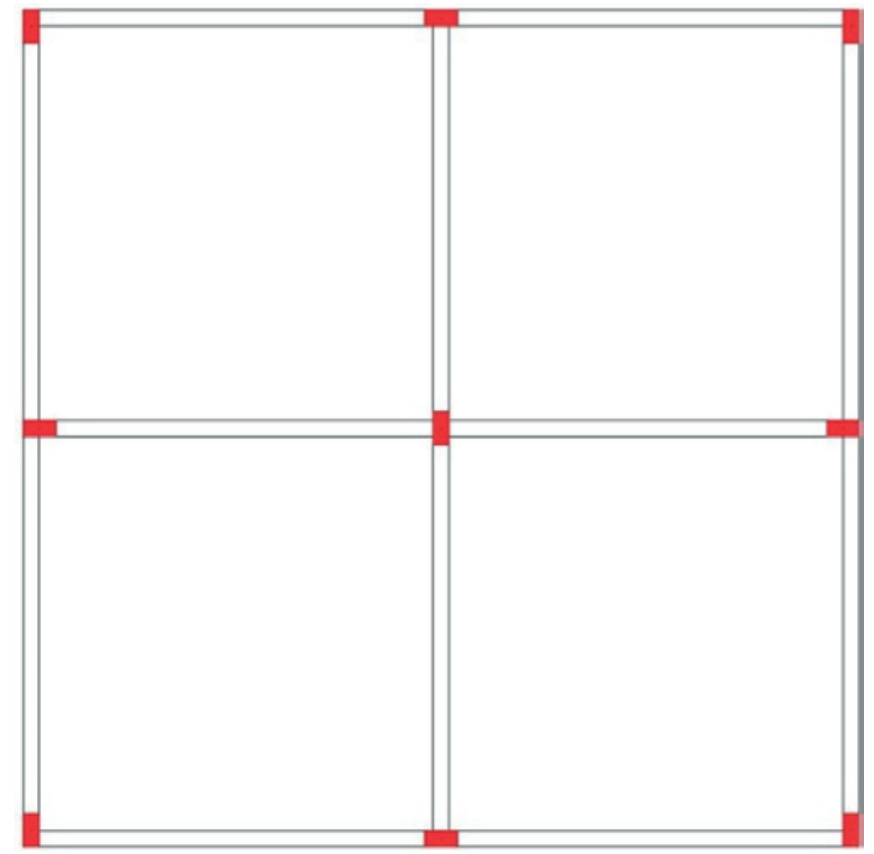

\section{Figure 2}

Plant of structural shapes $\mathrm{T}_{2}$ Source: Author
Table 2

Types of basic wind speed $\left(\mathrm{V}_{0}\right)$

\begin{tabular}{|c|c|}
\hline Nomenclature & Basic wind speed (m/s) \\
\hline$v_{1}$ & 30 \\
\hline$v_{2}$ & 50 \\
\hline Source: Author \\
\hline
\end{tabular}

Table 3

Types of characteristic strength of concrete $\left(f_{c k}\right)$

\begin{tabular}{|c|c|}
\hline Nomenclature & $\begin{array}{c}\text { Characteristic strength } \\
\text { of concrete (MPa) }\end{array}$ \\
\hline$f$ & 25 \\
\hline$g$ & 40 \\
\hline Source: Author \\
\hline
\end{tabular}

Table 4

Examples for simulations

\begin{tabular}{|c|c|c|c|}
\hline \multicolumn{4}{|c|}{ Combinations } \\
\hline $3 T_{1} \mathrm{Ev}_{1} \mathrm{f}$ & $3 \mathrm{~T}_{1} \mathrm{Ev}_{1} \mathrm{~g}$ & $3 \mathrm{~T}_{1} \mathrm{Ev}_{2} \mathrm{f}$ & $3 \mathrm{~T}_{1} \mathrm{Ev}_{2} \mathrm{~g}$ \\
\hline $3 \mathrm{~T}_{1} \mathrm{Fv}_{1} \mathrm{f}$ & $3 \mathrm{~T}_{1} \mathrm{Fv}_{1} \mathrm{~g}$ & $3 T_{1} \mathrm{Fv}_{2} \mathrm{f}$ & $3 \mathrm{~T}_{1} \mathrm{Fv}_{2} \mathrm{~g}$ \\
\hline $3 \mathrm{~T}_{2} \mathrm{Ev}_{1} \mathrm{f}$ & $3 \mathrm{~T}_{2} \mathrm{Ev}_{1} \mathrm{~g}$ & $3 \mathrm{~T}_{2} \mathrm{Ev}_{2} \mathrm{f}$ & $3 \mathrm{~T}_{2} \mathrm{Ev}_{2} \mathrm{~g}$ \\
\hline $3 \mathrm{~T}_{2} \mathrm{Fv}_{1} \mathrm{f}$ & $3 \mathrm{~T}_{2} \mathrm{Fv}_{1} \mathrm{~g}$ & $3 \mathrm{~T}_{2} \mathrm{Fv}_{2} \mathrm{f}$ & $3 \mathrm{~T}_{2} \mathrm{Fv}_{2} \mathrm{~g}$ \\
\hline $2 \mathrm{~T}_{1} \mathrm{G} \mathrm{v}_{1} \mathrm{f}$ & $2 \mathrm{~T}_{1} \mathrm{GV} \mathrm{v}_{1} \mathrm{~g}$ & $2 \mathrm{~T}_{1} \mathrm{Gv_{2 } \mathrm { f }}$ & $2 \mathrm{~T}_{1} \mathrm{G} \mathrm{v}_{2} \mathrm{~g}$ \\
\hline $2 \mathrm{~T}_{1} \mathrm{Hv}_{1} \mathrm{f}$ & $2 \mathrm{~T}_{1} \mathrm{Hv}_{1} \mathrm{~g}$ & $2 \mathrm{~T}_{1} \mathrm{Hv}_{2} \mathrm{f}$ & $2 \mathrm{~T}_{1} \mathrm{Hv}_{2} \mathrm{~g}$ \\
\hline $2 T_{2} G v_{1} f$ & $2 \mathrm{~T}_{2} G \mathrm{v}_{1} \mathrm{~g}$ & $2 \mathrm{~T}_{2} \mathrm{GV} \mathrm{v}_{2} \mathrm{f}$ & $2 \mathrm{~T}_{2} \mathrm{GV}_{2} \mathrm{~g}$ \\
\hline $2 \mathrm{~T}_{2} \mathrm{Hv}_{1} \mathrm{f}$ & $2 \mathrm{~T}_{2} \mathrm{Hv}_{1} \mathrm{~g}$ & $2 \mathrm{~T}_{2} \mathrm{Hv}_{2} \mathrm{f}$ & $2 \mathrm{~T}_{2} \mathrm{Hv}_{2} \mathrm{~g}$ \\
\hline $1 T_{1} I V_{1} f$ & $1 T_{1} / V_{1} g$ & $1 T_{1} I_{2} f$ & $1 \mathrm{~T}_{1} \mathrm{IV}_{2} \mathrm{~g}$ \\
\hline $1 T_{1} J V_{1} f$ & $1 \mathrm{~T}_{1} \mathrm{JV}_{1} \mathrm{~g}$ & $1 T_{1} J V_{2} f$ & $1 \mathrm{~T}_{1} \mathrm{JV}_{2} \mathrm{~g}$ \\
\hline $1 T_{2} V_{1} f$ & $1 \mathrm{~T}_{2} \mathrm{IV}_{1} \mathrm{~g}$ & $1 T_{2} I_{2} f$ & $1 \mathrm{~T}_{2} \mathrm{IV}_{2} \mathrm{~g}$ \\
\hline $1 T_{2} J V_{1} f$ & $1 \mathrm{~T}_{2} \mathrm{JV}_{1} \mathrm{~g}$ & $1 T_{2} J_{2} f$ & $1 \mathrm{~T}_{2} \mathrm{Jv}_{2} \mathrm{~g}$ \\
\hline
\end{tabular}


Table 5

Description of symbology adopted in table 4

\begin{tabular}{|c|c|}
\hline \multicolumn{2}{|c|}{ Symbology } \\
\hline Number of floors & $1,2,3$ \\
\hline Types of structural shapes & $T_{1}, T_{2}$ \\
\hline $\begin{array}{c}\text { Types of structural configurations } \\
\text { (Dimensions of beams, columns and slabs; } \\
\text { height of floot to floor; length of beams) }\end{array}$ & $\mathrm{E}, \mathrm{F}, \mathrm{G}, \mathrm{H}, \mathrm{I}, \mathrm{J}$ \\
\hline Types of $\mathrm{V}_{0}$ & $\mathrm{v}_{1}, \mathrm{v}_{2}$ \\
\hline Types of $\mathrm{f}_{\mathrm{ck}}$ & $\mathrm{f}, \mathrm{g}$ \\
\hline Source: Author & \\
\hline
\end{tabular}

timate the features compatible with those used in real buildings. Thus, Table 4 shows the list of simulated examples. The symbols used are listed in Table 5.

The variability used in designing the examples was adopted to obtain different detailing of the armor in the structural elements, and consequently, different rates of longitudinal armor. It should also be considered that the stiffness of structural elements is sensitive to the variation of the steel rate set for each structural element.

\subsection{Analysis of model examples}

Having defined the examples, the next step is to demonstrate their analysis. The analysis model is developed based on an iterative process to obtain the results, where, after the convergence, the average stiffness values obtained for beams and columns accurately represent the material nonlinearity, in an approximate manner, for the simulated example.

Figure 3 shows the simulation process of all examples on a flowchart.

\subsubsection{Processing 1}

Initially, the material nonlinearity is evaluated, approximately, with the values of stiffness for the beams $\left(\mathrm{El}_{\mathrm{sec}}=0,4 \cdot \mathrm{E}_{\mathrm{cic}} \mathrm{I}_{\mathrm{c}}\right.$ ) and the columns $\left(E I_{\text {sec }}=0,8 \cdot E_{c i c} I_{c}\right)$ - note that although these values are common for

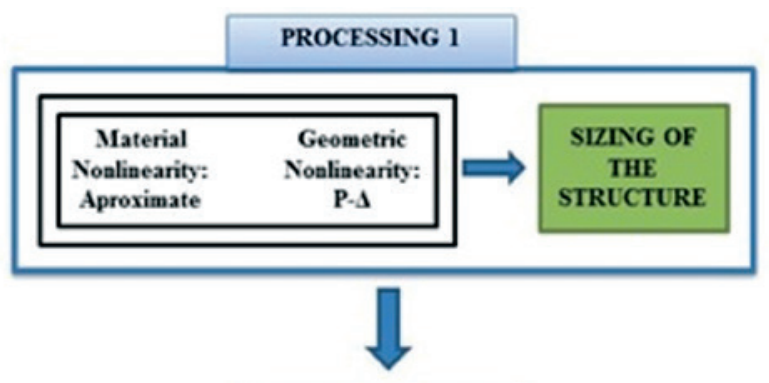

PROCESSING 2

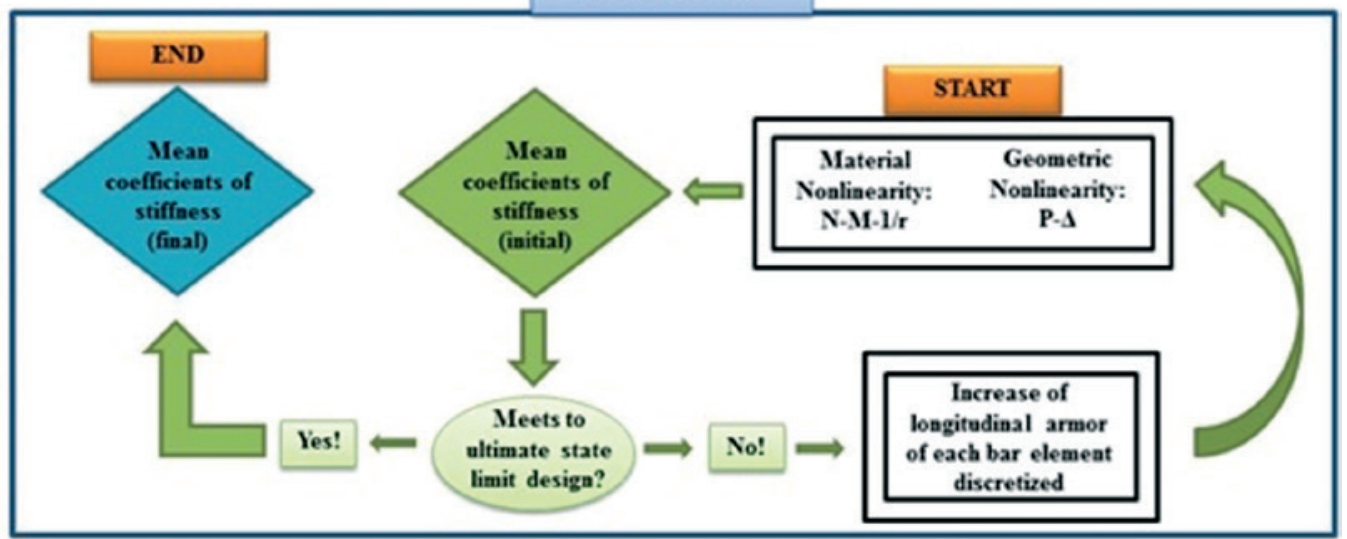

Figure 3

Analysis model of examples

Source: Author 
buildings with four or more floors, they were used as an initial measure. The geometric nonlinearity is analyzed by the P- $\Delta$ analysis.

After the estimation of global effects ( $1{ }^{\text {st }}$ order $+2^{\text {nd }}$ order $)$, we continue with the analysis of the local effects of second-order on the columns. As such, after setting the value of the total effects in each element, the dimensioning and detailing of structural elements is done, according to the parameters defined in the ABNT NBR 6118:2014.

\subsubsection{Processing 2}

On the basis of the material and geometric nonlinear portico the material nonlinearity is evaluated by $\mathrm{M}-1 / \mathrm{r}$ and $\mathrm{N}-\mathrm{M}-1 / \mathrm{r}$ diagrams, for beams and columns, respectively. Analogous to processing 1 , the geometric nonlinearity is evaluated by the P- $\Delta$ analysis.

This processing consists of only one verification with respect to the ultimate state limit design and provides the stiffness values for each bar element discretized from the beams and columns.

Such discretization is made for $50 \mathrm{~cm}$ long bar elements, as a similar performance is evident in preliminary tests for the discretization of $10 \mathrm{~cm}$ long bar elements. With respect to the savings on computational costs, the choice was justified.

For discretized bars that do not comply with the ultimate state limit

\section{Table 6}

Results of the simulations (part 1)

\begin{tabular}{|c|c|c|c|c|c|c|c|c|}
\hline Example & $\begin{array}{c}1^{\mathrm{a}} \\
\text { iteration }\end{array}$ & $\begin{array}{c}2^{a} \\
\text { iteration }\end{array}$ & $\begin{array}{c}3^{a} \\
\text { iteration }\end{array}$ & $\begin{array}{c}4^{a} \\
\text { iteration }\end{array}$ & $\begin{array}{c}5^{a} \\
\text { iteration }\end{array}$ & Estimated & $\begin{array}{c}\text { Average } \\
\text { rate of } \\
\text { beams } \\
\text { armor }(\%)\end{array}$ & $\begin{array}{c}\text { Average } \\
\text { rate of } \\
\text { columns } \\
\text { armor }(\%)\end{array}$ \\
\hline $3 T 1 \mathrm{Ev} l f$ & $\begin{array}{l}\alpha_{v}: 0,16 \\
\alpha_{p}: 0,75 \\
\end{array}$ & $\begin{array}{l}\alpha_{v}: 0,15 \\
\alpha_{p}: 0,72 \\
\end{array}$ & $\begin{array}{l}\alpha_{v}: 0,15 \\
\alpha_{p}: 0,71 \\
\end{array}$ & $\begin{array}{l}\alpha_{v}: 0,15 \\
\alpha_{p}: 0,72 \\
\end{array}$ & - & $\begin{array}{l}\alpha_{v}: 0,15 \\
\alpha_{p}: 0,72 \\
\end{array}$ & 0,92 & 0,73 \\
\hline 3T1Ev1g & $\begin{array}{l}\alpha_{v}: 0,13 \\
\alpha_{p}: 0,79 \\
\end{array}$ & $\begin{array}{l}\alpha_{v}: 0,12 \\
\alpha_{p}: 0,74 \\
\end{array}$ & $\begin{array}{l}\alpha_{v}: 0,12 \\
\alpha_{p}: 0,74 \\
\end{array}$ & - & - & $\begin{array}{l}\alpha_{v}: 0,12 \\
\alpha_{p}: 0,74 \\
\end{array}$ & 0,83 & 0,5 \\
\hline $3 T 1 \mathrm{Ev} 2 f$ & $\begin{array}{l}\alpha_{v}: 0,16 \\
\alpha_{p}: 0,74\end{array}$ & $\begin{array}{l}\alpha_{v}: 0,15 \\
\alpha_{p}: 0,71\end{array}$ & $\begin{array}{l}\alpha_{v}: 0,15 \\
\alpha_{p}: 0,71\end{array}$ & - & - & $\begin{array}{l}\alpha_{v}: 0,15 \\
\alpha_{p}: 0,71\end{array}$ & 0,92 & 0,76 \\
\hline $3 \mathrm{T1Ev} 2 \mathrm{~g}$ & $\begin{array}{l}\alpha_{v}: 0,13 \\
\alpha_{p}: 0,79\end{array}$ & $\begin{array}{l}\alpha_{v}: 0,13 \\
\alpha_{p}: 0,74\end{array}$ & $\begin{array}{l}\alpha_{v}: 0,13 \\
\alpha_{p}: 0,74\end{array}$ & - & - & $\begin{array}{l}\alpha_{v}: 0,13 \\
\alpha_{p}: 0,74\end{array}$ & 0,92 & 0,5 \\
\hline $3 T 1 F v l f$ & $\begin{array}{l}\alpha_{v}: 0,14 \\
\alpha_{p}: 0,77\end{array}$ & $\begin{array}{l}\alpha_{v}: 0,15 \\
\alpha_{p}: 0,73\end{array}$ & $\begin{array}{l}\alpha_{v}: 0,15 \\
\alpha_{p}: 0,73\end{array}$ & - & - & $\begin{array}{l}\alpha_{v}: 0,15 \\
\alpha_{p}: 0,73\end{array}$ & 0,75 & 0,59 \\
\hline 3T1Fv1g & $\begin{array}{l}\alpha_{v}: 0,11 \\
\alpha_{p}: 0,82\end{array}$ & $\begin{array}{l}\alpha_{\alpha}: 0,13 \\
\alpha_{p}: 0,77 \\
\end{array}$ & $\begin{array}{l}\alpha_{v}: 0,13 \\
\alpha_{p}: 0,77\end{array}$ & - & - & $\begin{array}{l}\alpha_{v}: 0,13 \\
\alpha_{p}: 0,77 \\
\end{array}$ & 0,69 & 0,59 \\
\hline $3 T 1 F v 2 f$ & $\begin{array}{l}\alpha_{:}: 0,14 \\
\alpha_{p}: 0,77\end{array}$ & $\begin{array}{l}\alpha_{\alpha}: 0,16 \\
\alpha_{p}: 0,73\end{array}$ & $\begin{array}{l}\alpha_{v}: 0,15 \\
\alpha_{p}: 0,73\end{array}$ & $\begin{array}{l}\alpha_{v}: 0,15 \\
\alpha_{p}: 0,73\end{array}$ & - & $\begin{array}{l}\alpha_{v}: 0,15 \\
\alpha_{p}: 0,73\end{array}$ & 0,8 & 0,6 \\
\hline $3 \mathrm{~T} 1 \mathrm{Fv} 2 \mathrm{~g}$ & $\begin{array}{l}\alpha_{:}: 0,11 \\
\alpha_{p}: 0,82\end{array}$ & $\begin{array}{l}\alpha_{\alpha}: 0,13 \\
\alpha_{p}: 0,77\end{array}$ & $\begin{array}{l}\alpha_{v}: 0,13 \\
\alpha_{p}: 0,77\end{array}$ & - & - & $\begin{array}{l}\alpha_{:}: 0,13 \\
\alpha_{p}: 0,77\end{array}$ & 0,72 & 0,59 \\
\hline $3 T 2 E v l f$ & $\begin{array}{l}\alpha_{:}: 0,18 \\
\alpha_{p}: 0,74\end{array}$ & $\begin{array}{l}\alpha_{:}: 0,15 \\
\alpha_{p}: 0,69\end{array}$ & $\begin{array}{l}\alpha_{v}: 0,15 \\
\alpha_{p}: 0,68\end{array}$ & $\begin{array}{l}\alpha_{v}: 0,15 \\
\alpha_{p}: 0,68\end{array}$ & - & $\begin{array}{l}\alpha_{:}: 0,15 \\
\alpha_{p}: 0,68\end{array}$ & 0,85 & 0,62 \\
\hline 3T2Ev1g & $\begin{array}{l}\alpha_{v}: 0,15 \\
\alpha_{0}: 0,78\end{array}$ & $\begin{array}{l}\alpha_{v}: 0,12 \\
\alpha_{\mathrm{p}}: 0,72\end{array}$ & $\begin{array}{l}\alpha_{v}: 0,12 \\
\alpha_{0}: 0,71\end{array}$ & $\begin{array}{l}\alpha_{v}: 0,12 \\
\alpha_{0}: 0,71\end{array}$ & - & $\begin{array}{l}\alpha_{v}: 0,12 \\
\alpha_{0}: 0,71\end{array}$ & 0,82 & 0,5 \\
\hline $3 T 2 E v 2 f$ & $\begin{array}{l}\alpha_{v}: 0,20 \\
\alpha_{p}: 0,72\end{array}$ & $\begin{array}{l}\alpha_{v}: 0,16 \\
\alpha_{p}: 0,68 \\
\end{array}$ & $\begin{array}{l}\alpha_{v}: 0,16 \\
\alpha_{p}: 0,68\end{array}$ & - & - & $\begin{array}{l}\alpha_{v}: 0,16 \\
\alpha_{p}: 0,68\end{array}$ & 1,03 & 0,83 \\
\hline $3 T 2 E v 2 g$ & $\begin{array}{l}\alpha_{v}: 0,17 \\
\alpha_{p}: 0,76 \\
\end{array}$ & $\begin{array}{l}\alpha_{\alpha}: 0,13 \\
\alpha_{p}: 0,70 \\
\end{array}$ & $\begin{array}{l}\alpha_{v}: 0,13 \\
\alpha_{p}: 0,70 \\
\end{array}$ & - & - & $\begin{array}{l}\alpha_{v}: 0,13 \\
\alpha_{p}: 0,70 \\
\end{array}$ & 0,96 & 0,56 \\
\hline $3 T 2 F v l f$ & $\begin{array}{l}\alpha_{v}: 0,14 \\
\alpha_{p}: 0,75 \\
\end{array}$ & $\begin{array}{l}\alpha_{\alpha}: 0,15 \\
\alpha_{p}: 0,70\end{array}$ & $\begin{array}{l}\alpha_{v}: 0,15 \\
\alpha_{p}: 0,70\end{array}$ & - & - & $\begin{array}{l}\alpha_{v}: 0,15 \\
\alpha_{p}: 0,70 \\
\end{array}$ & 0,72 & 0,6 \\
\hline $3 \mathrm{~T} 2 \mathrm{Fv} 1 \mathrm{~g}$ & $\begin{array}{l}\alpha_{v}: 0,11 \\
\alpha_{p}: 0,80\end{array}$ & $\begin{array}{l}\alpha_{v}: 0,13 \\
\alpha_{p}: 0,73\end{array}$ & $\begin{array}{l}\alpha_{v}: 0,13 \\
\alpha_{p}: 0,74\end{array}$ & $\begin{array}{l}\alpha_{v}: 0,13 \\
\alpha_{p}: 0,74\end{array}$ & - & $\begin{array}{l}\alpha_{v}: 0,13 \\
\alpha_{p}: 0,74\end{array}$ & 0,68 & 0,59 \\
\hline $3 \mathrm{~T} 2 \mathrm{Fv} 2 \mathrm{f}$ & $\begin{array}{l}\alpha_{v}: 0,14 \\
\alpha_{p}: 0,75\end{array}$ & $\begin{array}{l}\alpha_{v}: 0,16 \\
\alpha_{p}: 0,69\end{array}$ & $\begin{array}{l}\alpha_{v}: 0,16 \\
\alpha_{p}: 0,70\end{array}$ & $\begin{array}{l}\alpha_{v}: 0,16 \\
\alpha_{p}: 0,70\end{array}$ & - & $\begin{array}{l}\alpha_{v}: 0,16 \\
\alpha_{p}: 0,70\end{array}$ & 0,76 & 0,6 \\
\hline $3 \mathrm{~T} 2 \mathrm{Fv} 2 \mathrm{~g}$ & $\begin{array}{l}\alpha_{v}: 0,12 \\
\alpha_{p}: 0,79 \\
\end{array}$ & $\begin{array}{l}\alpha_{\alpha}: 0,14 \\
\alpha_{p}: 0,72 \\
\end{array}$ & $\begin{array}{l}\alpha_{v}: 0,14 \\
\alpha_{p}: 0,73 \\
\end{array}$ & $\begin{array}{l}\alpha_{v}: 0,14 \\
\alpha_{p}: 0,73 \\
\end{array}$ & - & $\begin{array}{l}\alpha_{v}: 0,14 \\
\alpha_{p}: 0,73 \\
\end{array}$ & 0,72 & 0,59 \\
\hline
\end{tabular}

Source: Author 
design, minimum increases are manually made in the respective areas of longitudinal armor and, then, the example undergoes another analysis with respect to material nonlinearity and geometric nonlinearity by means of the material and geometric nonlinear portico, obtaining new values of stiffness for each discretized bar. This process is repeated until all the elements comply with ultimate state limit design.

Subsequently, a note is made on the average values of stiffness provided by the software, for the whole set of beams and columns of the structure.

\subsubsection{Iterative process}

We replace the initial values of material nonlinearity (beams: $\mathrm{El}_{\text {sec }}=0,4 \cdot \mathrm{E}_{\mathrm{ci}} \mathrm{I}_{\mathrm{c}}$ and columns: $\mathrm{El}_{\mathrm{sec}}=0,8 \cdot \mathrm{E}_{\mathrm{ci}} \mathrm{I}_{\mathrm{c}}$ ) with the obtained coefficients (average values of stiffness) and repeat processing 1 and 2 . As the values of the coefficients are presented with an accuracy of two decimal places, this iterative process is repeated until the values of an iteration are equal to those of a previous iteration.

After convergence, the obtained values represent the evaluation of the material nonlinearity, in an approximate manner, for that structure.

Table 6

Results of the simulations (part 2)

\begin{tabular}{|c|c|c|c|c|c|c|c|c|}
\hline Example & $\begin{array}{c}1^{\mathrm{a}} \\
\text { iteration }\end{array}$ & $\begin{array}{c}2^{a} \\
\text { iteration }\end{array}$ & $\begin{array}{c}3^{a} \\
\text { iteration }\end{array}$ & $\begin{array}{c}4^{a} \\
\text { iteration }\end{array}$ & $\begin{array}{c}5^{a} \\
\text { iteration }\end{array}$ & Estimated & $\begin{array}{c}\text { Average } \\
\text { rate of } \\
\text { beams } \\
\text { armor (\%) }\end{array}$ & $\begin{array}{l}\text { Average } \\
\text { rate of } \\
\text { columns } \\
\text { armor }(\%)\end{array}$ \\
\hline 2T1Gvif & $\begin{array}{l}\alpha_{v}: 0,18 \\
\alpha_{p}: 0,70\end{array}$ & $\begin{array}{l}\alpha_{v}: 0,18 \\
\alpha_{p}: 0,69\end{array}$ & $\begin{array}{l}\alpha_{v}: 0,18 \\
\alpha_{p}: 0,69\end{array}$ & - & - & $\begin{array}{l}\alpha_{v}: 0,18 \\
\alpha_{p}: 0,69\end{array}$ & 1,34 & 0,85 \\
\hline 2T1Gvlg & $\begin{array}{l}\alpha_{:}: 0,15 \\
\alpha_{p}: 0,74\end{array}$ & $\begin{array}{l}\alpha_{\alpha}: 0,15 \\
\alpha_{p}: 0,71\end{array}$ & $\begin{array}{l}\alpha_{v}: 0,15 \\
\alpha_{p}: 0,71\end{array}$ & - & - & $\begin{array}{l}\alpha_{:}: 0,15 \\
\alpha_{p}: 0,71\end{array}$ & 1,26 & 0,7 \\
\hline 2T1Gv2f & $\begin{array}{l}\alpha_{v}: 0,18 \\
\alpha_{p}: 0,70\end{array}$ & $\begin{array}{l}\alpha_{v}: 0,18 \\
\alpha_{p}: 0,69\end{array}$ & $\begin{array}{l}\alpha_{v}: 0,18 \\
\alpha_{p}: 0,69\end{array}$ & - & - & $\begin{array}{l}\alpha_{v}: 0,18 \\
\alpha_{p}: 0,69\end{array}$ & 1,28 & 0,87 \\
\hline $2 \mathrm{~T} 1 \mathrm{G} v 2 \mathrm{~g}$ & $\begin{array}{l}\alpha_{v}: 0,15 \\
\alpha_{p}: 0,75\end{array}$ & $\begin{array}{l}\alpha_{v}: 0,14 \\
\alpha_{p}: 0,72\end{array}$ & $\begin{array}{l}\alpha_{v}: 0,14 \\
\alpha_{p}: 0,72\end{array}$ & - & - & $\begin{array}{l}\alpha_{v}: 0,14 \\
\alpha_{p}: 0,72\end{array}$ & 1,24 & 0,74 \\
\hline $2 \mathrm{TlHvlf}$ & $\begin{array}{l}\alpha_{v}: 0,15 \\
\alpha_{p}: 0,81 \\
\end{array}$ & $\begin{array}{l}\alpha_{\alpha}: 0,16 \\
\alpha_{p}: 0,76\end{array}$ & $\begin{array}{l}\alpha_{v}: 0,15 \\
\alpha_{p}: 0,76\end{array}$ & $\begin{array}{l}\alpha_{v}: 0,15 \\
\alpha_{p}: 0,76\end{array}$ & - & $\begin{array}{l}\alpha_{v}: 0,15 \\
\alpha_{p}: 0,76 \\
\end{array}$ & 0,81 & 1,03 \\
\hline 2T1Hvlg & $\begin{array}{l}\alpha_{:}: 0,13 \\
\alpha_{p}: 0,84\end{array}$ & $\begin{array}{l}\alpha_{\alpha}: 0,14 \\
\alpha_{p}: 0,78\end{array}$ & $\begin{array}{l}\alpha_{v}: 0,13 \\
\alpha_{p}: 0,78\end{array}$ & $\begin{array}{l}\alpha_{:}: 0,14 \\
\alpha_{p}: 0,78\end{array}$ & - & $\begin{array}{l}\alpha_{:}: 0,14 \\
\alpha_{p}: 0,78\end{array}$ & 0,81 & 0,79 \\
\hline $2 \mathrm{~T} 1 \mathrm{Hv} 2 \mathrm{f}$ & $\begin{array}{l}\alpha_{:}: 0,15 \\
\alpha_{p}: 0,82\end{array}$ & $\begin{array}{l}\alpha_{\alpha}: 0,15 \\
\alpha_{p}: 0,76\end{array}$ & $\begin{array}{l}\alpha_{v}: 0,15 \\
\alpha_{p}: 0,76\end{array}$ & - & - & $\begin{array}{l}\alpha_{:}: 0,15 \\
\alpha_{p}: 0,76\end{array}$ & 0,79 & 1,01 \\
\hline $2 \mathrm{~T} 1 \mathrm{Hv} 2 \mathrm{~g}$ & $\begin{array}{l}\alpha_{v}: 0,13 \\
\alpha_{p}: 0,85\end{array}$ & $\begin{array}{l}\alpha_{v}: 0,14 \\
\alpha_{p}: 0,78\end{array}$ & $\begin{array}{l}\alpha_{v}: 0,13 \\
\alpha_{0}: 0,79\end{array}$ & $\begin{array}{l}\alpha_{v}: 0,14 \\
\alpha_{p}: 0,78\end{array}$ & - & $\begin{array}{l}\alpha_{v}: 0,14 \\
\alpha_{0}: 0,78\end{array}$ & 0,83 & 0,79 \\
\hline 2T2Gv1f & $\begin{array}{l}\alpha_{v}: 0,18 \\
\alpha_{0}: 0,68\end{array}$ & $\begin{array}{l}\alpha_{v}: 0,18 \\
\alpha_{p}: 0,65\end{array}$ & $\begin{array}{l}\alpha_{v}: 0,18 \\
\alpha_{0}: 0,65\end{array}$ & - & - & $\begin{array}{l}\alpha_{v}: 0,18 \\
\alpha_{p}: 0,65\end{array}$ & 1,27 & 0,76 \\
\hline $2 \mathrm{~T} 2 \mathrm{Gv} 1 \mathrm{~g}$ & $\begin{array}{l}\alpha_{v}: 0,15 \\
\alpha_{0}: 0,72\end{array}$ & $\begin{array}{l}\alpha_{v}: 0,15 \\
\alpha_{p}: 0,67\end{array}$ & $\begin{array}{l}\alpha_{v}: 0,15 \\
\alpha_{0}: 0,67\end{array}$ & - & - & $\begin{array}{l}\alpha_{v}: 0,15 \\
\alpha_{0}: 0,67\end{array}$ & 1,17 & 0,66 \\
\hline $2 T 2 G v 2 f$ & $\begin{array}{l}\alpha_{v}: 0,19 \\
\alpha_{p}: 0,67\end{array}$ & $\begin{array}{l}\alpha_{2}: 0,18 \\
\alpha_{p}: 0,65\end{array}$ & $\begin{array}{l}\alpha_{v}: 0,19 \\
\alpha_{p}: 0,64\end{array}$ & $\begin{array}{l}\alpha_{v}: 0,18 \\
\alpha_{p}: 0,65\end{array}$ & - & $\begin{array}{l}\alpha_{v}: 0,18 \\
\alpha_{p}: 0,65\end{array}$ & 1,31 & 0,88 \\
\hline $2 \mathrm{~T} 2 \mathrm{G} v 2 \mathrm{~g}$ & $\begin{array}{l}\alpha_{v}: 0,15 \\
\alpha_{p}: 0,70\end{array}$ & $\begin{array}{l}\alpha_{\alpha}: 0,15 \\
\alpha_{p}: 0,66\end{array}$ & $\begin{array}{l}\alpha_{v}: 0,15 \\
\alpha_{p}: 0,66\end{array}$ & - & - & $\begin{array}{l}\alpha_{:}: 0,15 \\
\alpha_{p}: 0,66\end{array}$ & 1,26 & 0,78 \\
\hline $2 \mathrm{~T} 2 \mathrm{Hv} l f$ & $\begin{array}{l}\alpha_{v}: 0,16 \\
\alpha_{p}: 0,80\end{array}$ & $\begin{array}{l}\alpha_{v}: 0,16 \\
\alpha_{p}: 0,73\end{array}$ & $\begin{array}{l}\alpha_{v}: 0,16 \\
\alpha_{p}: 0,73\end{array}$ & - & - & $\begin{array}{l}\alpha_{v}: 0,16 \\
\alpha_{p}: 0,73\end{array}$ & 0,8 & 0,93 \\
\hline $2 \mathrm{~T} 2 \mathrm{Hv} 1 \mathrm{~g}$ & $\begin{array}{l}\alpha_{v}: 0,14 \\
\alpha_{p}: 0,82 \\
\end{array}$ & $\begin{array}{l}\alpha_{v}: 0,14 \\
\alpha_{p}: 0,75\end{array}$ & $\begin{array}{l}\alpha_{v}: 0,14 \\
\alpha_{p}: 0,75 \\
\end{array}$ & - & - & $\begin{array}{l}\alpha_{v}: 0,14 \\
\alpha_{p}: 0,75 \\
\end{array}$ & 0,73 & 0,79 \\
\hline $2 \mathrm{~T} 2 \mathrm{Hv} 2 \mathrm{~g}$ & $\begin{array}{l}\alpha_{v}: 0,14 \\
\alpha_{p}: 0,81\end{array}$ & $\begin{array}{l}\alpha_{\alpha}: 0,14 \\
\alpha_{p}: 0,73 \\
\end{array}$ & $\begin{array}{l}\alpha_{v}: 0,14 \\
\alpha_{p}: 0,73 \\
\end{array}$ & - & - & $\begin{array}{l}\alpha_{:}: 0,14 \\
\alpha_{p}: 0,73 \\
\end{array}$ & 0,76 & 0,79 \\
\hline $1 T 1 l v 1 f$ & $\begin{array}{l}\alpha_{:}: 0,19 \\
\alpha_{p}: 0,68\end{array}$ & $\begin{array}{l}\alpha_{\alpha}: 0,17 \\
\alpha_{p}: 0,64\end{array}$ & $\begin{array}{l}\alpha_{v}: 0,17 \\
\alpha_{p}: 0,65\end{array}$ & $\begin{array}{l}\alpha_{v}: 0,17 \\
\alpha_{p}: 0,65\end{array}$ & - & $\begin{array}{l}\alpha_{:}: 0,17 \\
\alpha_{p}: 0,65\end{array}$ & 1,06 & 0,46 \\
\hline
\end{tabular}

Source: Author 


\subsection{Statistical treatment}

With the stiffness values estimated in each example owing to the iterative process, one should perform the statistical treatment to obtain the average values of the stiffness reducing coefficients for evaluation of the material nonlinearity, in an approximate manner, for buildings with one, two and three floors.

Thus, the measures used to describe the set of values obtained in each example are measures of central tendency (representative average) and measures of dispersion (standard deviation, coefficient of variation, and maximum and minimum values). We also used Gaussian distribution graph $\mathrm{x}$ histogram, to compare the distribution mathematically established with the one that represents the numerically obtained data.

The representative average is the value that the data of a distribution concentrates the most and, for the purpose of this study, it can be defined by equation 6 .

$\overline{\alpha_{(v / p)}}=\frac{1}{n} \cdot \sum_{i=1}^{n} \alpha_{(v / p) i}$

where

$\mathrm{n}$ : number of simulated examples;

$\overline{\alpha_{(v / p)}}$ : average stiffness reduction coefficient of beams or columns;

$\alpha_{(v / p) i}$ : stiffness reducing coefficient of the beams or columns, obtained in each example.

The standard deviation represents the variation or dispersion that

\section{Table 6}

Results of the simulations (part 2)

\begin{tabular}{|c|c|c|c|c|c|c|c|c|}
\hline Example & $1^{a}$ & $\begin{array}{c}2^{a} \\
\text { iteration }\end{array}$ & $\begin{array}{c}3^{a} \\
\text { iteration }\end{array}$ & $\begin{array}{c}4^{a} \\
\text { iteration }\end{array}$ & $\begin{array}{c}5^{a} \\
\text { iteration }\end{array}$ & Estimated & $\begin{array}{c}\text { Average } \\
\text { rate of } \\
\text { beams } \\
\text { armor (\%) }\end{array}$ & $\begin{array}{l}\text { Average } \\
\text { rate of } \\
\text { columns } \\
\text { armor (\%) }\end{array}$ \\
\hline $1 \mathrm{~T} 1 \mathrm{lv} 1 \mathrm{~g}$ & $\begin{array}{l}\alpha_{v}: 0,16 \\
\alpha_{p}: 0,71\end{array}$ & $\begin{array}{l}\alpha_{v}: 0,14 \\
\alpha_{p}: 0,64\end{array}$ & $\begin{array}{l}\alpha_{v}: 0,14 \\
\alpha_{p}: 0,64\end{array}$ & - & - & $\begin{array}{l}\alpha_{v}: 0,14 \\
\alpha_{p}: 0,64\end{array}$ & 1,12 & 0,73 \\
\hline $1 T 1$ lv2f & $\begin{array}{l}\alpha_{v}: 0,19 \\
\alpha_{p}: 0,67\end{array}$ & $\begin{array}{l}\alpha_{v}: 0,17 \\
\alpha_{p}: 0,65\end{array}$ & $\begin{array}{l}\alpha_{v}: 0,17 \\
\alpha_{p}: 0,64\end{array}$ & $\begin{array}{l}\alpha_{v}: 0,17 \\
\alpha_{p}: 0,64\end{array}$ & - & $\begin{array}{l}\alpha_{v}: 0,17 \\
\alpha_{p}: 0,64\end{array}$ & 1,09 & 0,8 \\
\hline $1 \mathrm{T1} / \mathrm{lv} 2 \mathrm{~g}$ & $\begin{array}{l}\alpha_{v}: 0,16 \\
\alpha_{p}: 0,71\end{array}$ & $\begin{array}{l}\alpha_{v}: 0,14 \\
\alpha_{p}: 0,65\end{array}$ & $\begin{array}{l}\alpha_{v}: 0,14 \\
\alpha_{p}: 0,64\end{array}$ & $\begin{array}{l}\alpha_{v}: 0,14 \\
\alpha_{p}: 0,64\end{array}$ & - & $\begin{array}{l}\alpha_{v}: 0,14 \\
\alpha_{p}: 0,64\end{array}$ & 1,07 & 0,73 \\
\hline 1T1Jv1f & $\begin{array}{l}\alpha_{v}: 0,17 \\
\alpha_{p}: 0,76\end{array}$ & $\begin{array}{l}\alpha_{v}: 0,19 \\
\alpha_{p}: 0,73\end{array}$ & $\begin{array}{l}\alpha_{v}: 0,19 \\
\alpha_{p}: 0,73\end{array}$ & - & - & $\begin{array}{l}\alpha_{v}: 0,19 \\
\alpha_{p}: 0,73\end{array}$ & 1,27 & 1,42 \\
\hline $1 \mathrm{~T} 1 \mathrm{Jv} 1 \mathrm{~g}$ & $\begin{array}{l}\alpha_{v}: 0,14 \\
\alpha_{p}: 0,78\end{array}$ & $\begin{array}{l}\alpha_{v}: 0,15 \\
\alpha_{p}: 0,73\end{array}$ & $\begin{array}{l}\alpha_{v}: 0,15 \\
\alpha_{p}: 0,73\end{array}$ & - & - & $\begin{array}{l}\alpha_{v}: 0,15 \\
\alpha_{p}: 0,73\end{array}$ & 1,12 & 1,25 \\
\hline $1 T 1 J v 2 f$ & $\begin{array}{l}\alpha_{v}: 0,17 \\
\alpha_{p}: 0,75\end{array}$ & $\begin{array}{l}\alpha_{v}: 0,19 \\
\alpha_{p}: 0,73\end{array}$ & $\begin{array}{l}\alpha_{v}: 0,19 \\
\alpha_{p}: 0,73\end{array}$ & - & - & $\begin{array}{l}\alpha_{v}: 0,19 \\
\alpha_{p}: 0,73\end{array}$ & 1,25 & 1,55 \\
\hline $1 \mathrm{~T} 1 \mathrm{Jv} 2 \mathrm{~g}$ & $\begin{array}{l}\alpha_{v}: 0,14 \\
\alpha_{p}: 0,78\end{array}$ & $\begin{array}{l}\alpha_{v}: 0,15 \\
\alpha_{p}: 0,73\end{array}$ & $\begin{array}{l}\alpha_{v}: 0,15 \\
\alpha_{p}: 0,73\end{array}$ & - & - & $\begin{array}{l}\alpha_{v}: 0,15 \\
\alpha_{p}: 0,73\end{array}$ & 1,12 & 1,29 \\
\hline 1T2lv1f & $\begin{array}{l}\alpha_{v}: 0,21 \\
\alpha_{p}: 0,67\end{array}$ & $\begin{array}{l}\alpha_{v}: 0,19 \\
\alpha_{p}: 0,62\end{array}$ & $\begin{array}{l}\alpha_{v}: 0,19 \\
\alpha_{p}: 0,62\end{array}$ & - & - & $\begin{array}{l}\alpha_{v}: 0,19 \\
\alpha_{p}: 0,62\end{array}$ & 1,11 & 0,56 \\
\hline 1T2lv1g & $\begin{array}{l}\alpha_{v}: 0,18 \\
\alpha_{p}: 0,71\end{array}$ & $\begin{array}{l}\alpha_{v}: 0,15 \\
\alpha_{p}: 0,63\end{array}$ & $\begin{array}{l}\alpha_{v}: 0,15 \\
\alpha_{p}: 0,62\end{array}$ & $\begin{array}{l}\alpha_{v}: 0,15 \\
\alpha_{p}: 0,62 \\
\end{array}$ & - & $\begin{array}{l}\alpha_{v}: 0,15 \\
\alpha_{p}: 0,62\end{array}$ & 1,03 & 0,56 \\
\hline 1T2Iv2f & $\begin{array}{l}\alpha_{v}: 0,21 \\
\alpha_{p}: 0,66\end{array}$ & $\begin{array}{l}\alpha_{v}: 0,19 \\
\alpha_{p}: 0,62\end{array}$ & $\begin{array}{l}\alpha_{v}: 0,19 \\
\alpha_{p}: 0,62\end{array}$ & - & - & $\begin{array}{l}\alpha_{v}: 0,19 \\
\alpha_{p}: 0,62\end{array}$ & 1,05 & 0,59 \\
\hline $1 \mathrm{~T} 2 \mathrm{lv} 2 \mathrm{~g}$ & $\begin{array}{l}\alpha_{v}: 0,18 \\
\alpha_{p}: 0,70\end{array}$ & $\begin{array}{l}\alpha_{v}: 0,16 \\
\alpha_{p}: 0,62\end{array}$ & $\begin{array}{l}\alpha_{v}: 0,15 \\
\alpha_{p}: 0,62\end{array}$ & $\begin{array}{l}\alpha_{v}: 0,16 \\
\alpha_{p}: 0,62\end{array}$ & $\begin{array}{l}\alpha_{v}: 0,15 \\
\alpha_{p}: 0,62\end{array}$ & $\begin{array}{l}\alpha_{v}: 0,15 \\
\alpha_{p}: 0,62\end{array}$ & 1,06 & 0,56 \\
\hline 1T2Jv1f & $\begin{array}{l}\alpha_{v}: 0,17 \\
\alpha_{p}: 0,73\end{array}$ & $\begin{array}{l}\alpha_{v}: 0,20 \\
\alpha_{p}: 0,69\end{array}$ & $\begin{array}{l}\alpha_{v}: 0,21 \\
\alpha_{p}: 0,69\end{array}$ & $\begin{array}{l}\alpha_{v}: 0,21 \\
\alpha_{p}: 0,69\end{array}$ & - & $\begin{array}{l}\alpha_{v}: 0,21 \\
\alpha_{p}: 0,69\end{array}$ & 1,25 & 1,35 \\
\hline 1T2Jv1g & $\begin{array}{l}\alpha_{v}: 0,14 \\
\alpha_{p}: 0,75\end{array}$ & $\begin{array}{l}\alpha_{v}: 0,16 \\
\alpha_{p}: 0,67\end{array}$ & $\begin{array}{l}\alpha_{v}: 0,17 \\
\alpha_{p}: 0,68\end{array}$ & $\begin{array}{l}\alpha_{v}: 0,17 \\
\alpha_{p}: 0,67\end{array}$ & $\begin{array}{l}\alpha_{v}: 0,17 \\
\alpha_{p}: 0,67\end{array}$ & $\begin{array}{l}\alpha_{v}: 0,17 \\
\alpha_{p}: 0,67\end{array}$ & 1,17 & 0,94 \\
\hline 1T2Jv2f & $\begin{array}{l}\alpha_{v}: 0,16 \\
\alpha_{p}: 0,73\end{array}$ & $\begin{array}{l}\alpha_{v}: 0,20 \\
\alpha_{p}: 0,68\end{array}$ & $\begin{array}{l}\alpha_{v}: 0,20 \\
\alpha_{p}: 0,69\end{array}$ & $\begin{array}{l}\alpha_{v}: 0,20 \\
\alpha_{p}: 0,69\end{array}$ & - & $\begin{array}{l}\alpha_{v}: 0,20 \\
\alpha_{p}: 0,69\end{array}$ & 1,24 & 1,4 \\
\hline 1T2Jv2g & $\begin{array}{l}\alpha_{v}: 0,13 \\
\alpha_{p}: 0,76\end{array}$ & $\begin{array}{l}\alpha_{v}: 0,15 \\
\alpha_{p}: 0,68\end{array}$ & $\begin{array}{l}\alpha_{v}: 0,17 \\
\alpha_{p}: 0,67\end{array}$ & $\begin{array}{l}\alpha_{v}: 0,17 \\
\alpha_{p}: 0,67\end{array}$ & - & $\begin{array}{l}\alpha_{v}: 0,17 \\
\alpha_{p}: 0,67\end{array}$ & 1,15 & 0,94 \\
\hline
\end{tabular}

Source: Author 


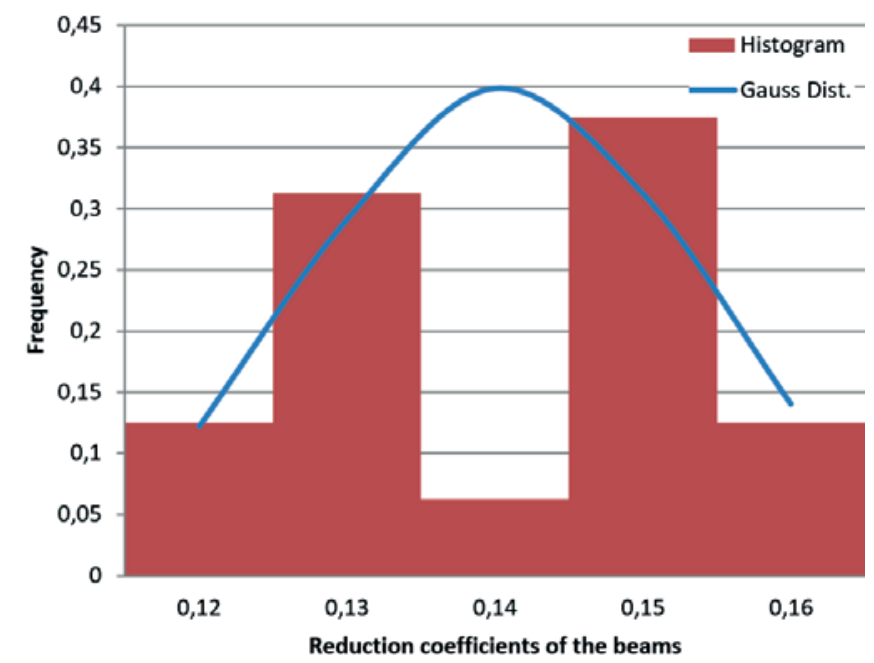

Figure 4

Gauss distribution graph $\mathrm{x}$ histogram for the beams stiffness in examples with 3 floors

Source: Author

exists relative to the average for a given set of data and, for the purpose of this study it can be defined by equation 7 .

$s=\sqrt{\frac{1}{n-1} \cdot \sum_{i=1}^{n}\left(\alpha_{(v / p) i}-\overline{\alpha_{(v / p)}}\right)^{2}}$

where

$\mathrm{s}$ : standard deviation;

$\overline{\alpha_{(v / p)}}:$ average stiffness reduction coefficient of beams or columns;

$\alpha_{(v / p) i}$ : stiffness reducing coefficient of the beams or columns, obtained in each example.

The standard deviation represents the variation or dispersion that exists relative to the average for a given set of data and, for the purpose of this study it can be defined by equation 7 .

The coefficient of variation is a measure of relative dispersion, used for the accuracy of estimates and represents the standard deviation as a percentage of the average. For the purpose of this study, it can be defined by equation 8 .

\section{Table 7}

Result of statistical analysis for the beams stiffness in examples with 3 floors

\begin{tabular}{|c|c|}
\hline \multicolumn{2}{|c|}{ Descriptive statistics } \\
\hline Average representative & 0,140625 \\
\hline Standard deviation & 0,013400871 \\
\hline Variation coefficient & $9,53 \%$ \\
\hline Number of idealized examples & 16 \\
\hline Minimum value & 0,12 \\
\hline Maximum value & 0,16 \\
\hline Source: Author \\
\hline
\end{tabular}

$\mathrm{c}_{\mathrm{v}}=\frac{\mathrm{s}}{\frac{\alpha_{(\mathrm{v} / \mathrm{p})}}{2}} \cdot 100$

where

$\mathrm{C}_{\mathrm{v}}$ : coefficient of variation expressed in percentage (\%)

$\mathrm{s}$ : standard deviation;

$\overline{\alpha_{(v / p)}}$ : average stiffness reduction coefficient of beams or columns. Therefore, the lower the value of the variation coefficient, the more homogeneous will be the data, i.e., the smaller will be the dispersion around the average. In general, the coefficient of variation can be evaluated as follows:

$c_{v} \leq 15 \%$ : low dispersion (homogeneous data);

- $15 \%<\mathrm{c}_{\mathrm{v}} \leq 30 \%$ : average dispersion;

- $c_{v}>30 \%:$ high dispersion (heterogeneous data).

\section{Results and discussions}

For each conceived example, their respective stiffness values for For each conceived example, their respective stiffness values for the whole set of beams $\left(E_{\mathrm{sec}}=\alpha_{v} \cdot E_{\mathrm{cic}_{\mathrm{c}}}\right)$ and columns $\left(E_{\text {sec }}=\alpha_{p} \cdot E_{c i c}\right)$ were obtained. Table 6 shows the values obtained for each iteration and the estimated value that represents the material nonlinearity, in an approximate manner, in each analyzed sample. After obtaining the estimated values of the stiffness reducing coefficients in each example described in Table 6, the statistical treatment was commenced to obtain the average values of the stiffness reduction coefficients for the evaluation of the material nonlinearity, in an approximate manner, in buildings with one, two, and three floors The results of this statistical treatment are described below.

\subsection{Buildings with three floors}

\subsubsection{Average stiffness reduction coefficient for beams}

In Figure 4, we can see the Gauss distribution graph $\mathrm{x}$ histogram

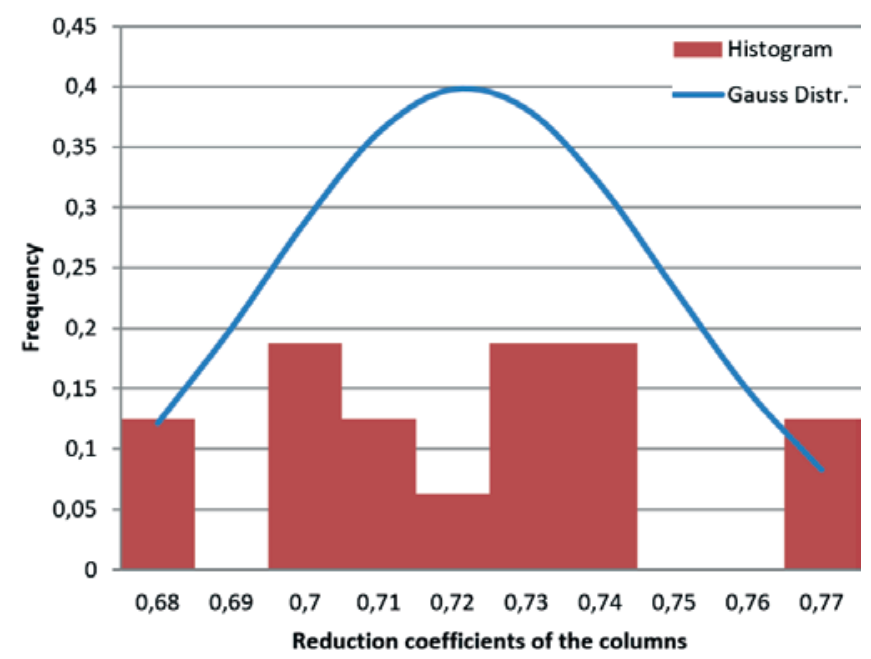

\section{Figure 5}

Gauss distribution graph $\mathrm{x}$ histogram for the columns stiffness in examples with 3 floors Source: Author 


\section{Table 8}

Result of statistical analysis for the beams stiffness in examples with 3 floors

\begin{tabular}{|c|c|}
\hline \multicolumn{2}{|c|}{ Descriptive statistics } \\
\hline Average representative & 0,721875 \\
\hline Standard deviation & 0,027133927 \\
\hline Variation coefficient & $3,76 \%$ \\
\hline Number of idealized examples & 16 \\
\hline Minimum value & 0,68 \\
\hline Maximum value & 0,77 \\
\hline Source: Author \\
\hline
\end{tabular}

and, in Table 7, we present the values of the representative average, standard deviation, coefficient of variation, and the maximum and minimum values.

\subsubsection{Average stiffness reduction coefficient for columns}

In Figure 5, we can see the Gauss distribution graph $\mathrm{x}$ histogram and, in Table 8, we present the values of the representative average, standard deviation, coefficient of variation, and the maximum and minimum values.

\subsection{Buildings with two floors}

\subsubsection{Average stiffness reduction coefficient} for beams

In Figure 6, we can see the Gauss distribution graph $x$ histogram and, in Table 9, we present the values of the representative

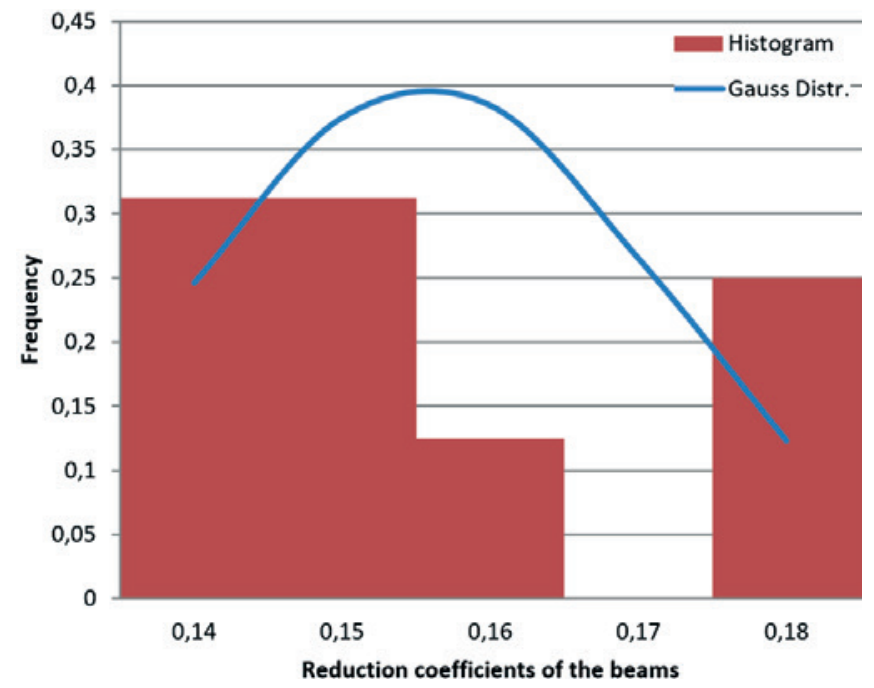

Figure 6

Gauss distribution graph $\mathrm{x}$ histogram for the beams stiffness in examples with 2 floors Source: Author

\section{Table 9}

Result of statistical analysis for the beams stiffness in examples with 2 floors

\begin{tabular}{|c|c|}
\hline \multicolumn{2}{|c|}{ Descriptive statistics } \\
\hline Average representative & 0,155625 \\
\hline Standard deviation & 0,015903354 \\
\hline Variation coefficient & $10,22 \%$ \\
\hline Number of idealized examples & 16 \\
\hline Minimum value & 0,14 \\
\hline Maximum value & 0,18 \\
\hline Source: Author
\end{tabular}

average, standard deviation, coefficient of variation, and the maximum and minimum values.

\subsubsection{Average stiffness reduction coefficient for columns}

In Figure 7, we can see the Gauss distribution graph $\mathrm{x}$ histogram and, in Table 10, we present the values of the representative average, standard deviation, coefficient of variation, and the maximum and minimum values.

\subsection{Buildings with 1 floor}

\subsubsection{Average stiffness reduction coefficient for beams}

In Figure 8, we can see the Gauss distribution graph $\mathrm{x}$ histogram and, in Table 11, we present the values of the representative average, standard deviation, coefficient of variation, and the maximum and minimum values.

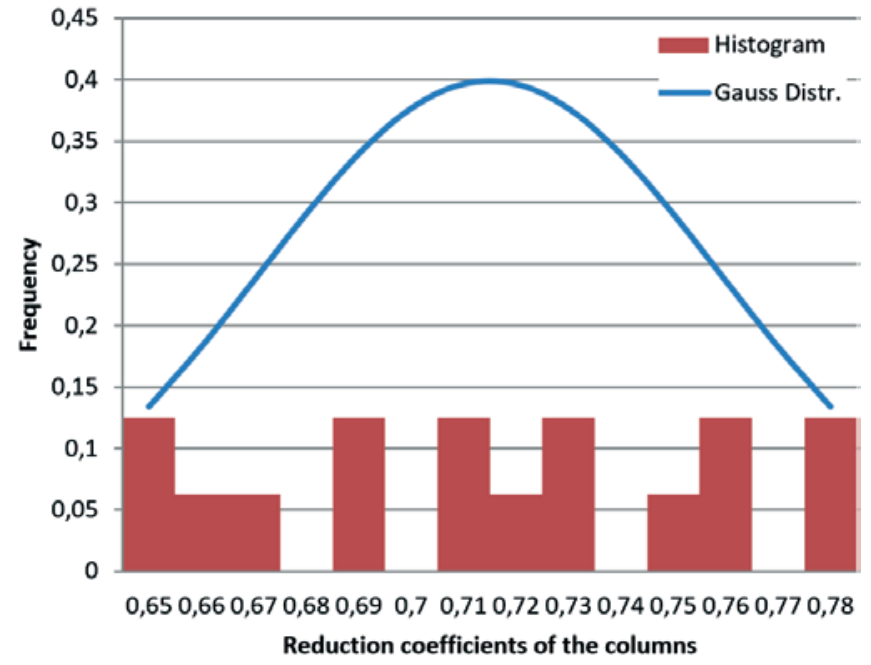

Figure 7

Gauss distribution graph $\mathrm{x}$ histogram for the columns stiffness in examples with 2 floors Source: Author 
Table 10

Result of statistical analysis for the beams stiffness in examples with 2 floors

\begin{tabular}{|c|c|}
\hline \multicolumn{2}{|c|}{ Descriptive statistics } \\
\hline Average representative & 0,715 \\
\hline Standard deviation & 0,043969687 \\
\hline Variation coefficient & $6,15 \%$ \\
\hline Number of idealized examples & 16 \\
\hline Minimum value & 0,65 \\
\hline Maximum value & 0,78 \\
\hline Source: Author \\
\hline
\end{tabular}

\subsubsection{Average stiffness reduction coefficient for columns}

In Figure 9, we can see the Gauss distribution graph $\mathrm{x}$ histogram and, in Table 12, we present the values of the representative average, standard deviation, coefficient of variation, and the maximum and minimum values.

\subsection{Proposal of stiffness values for beams and columns}

According to the obtained variation coefficients, the obtained representative averages show a low-dispersion around the average, owing to the homogeneity of the data, the averages represent satisfactorily the values of stiffness for the set of beams and columns obtained in each designed example.

Therefore, in Table 13 we present the stiffness values for beams $\left(\mathrm{El}_{\mathrm{sec}}=\alpha_{\mathrm{v}} \cdot \mathrm{E}_{\mathrm{cic}} \mathrm{I}_{\mathrm{c}}\right)$ and columns $\left(\mathrm{El}_{\mathrm{sec}}=\alpha_{\mathrm{p}} \cdot \mathrm{E}_{\mathrm{ci}} \mathrm{I}_{\mathrm{c}}\right)$ for the approximate

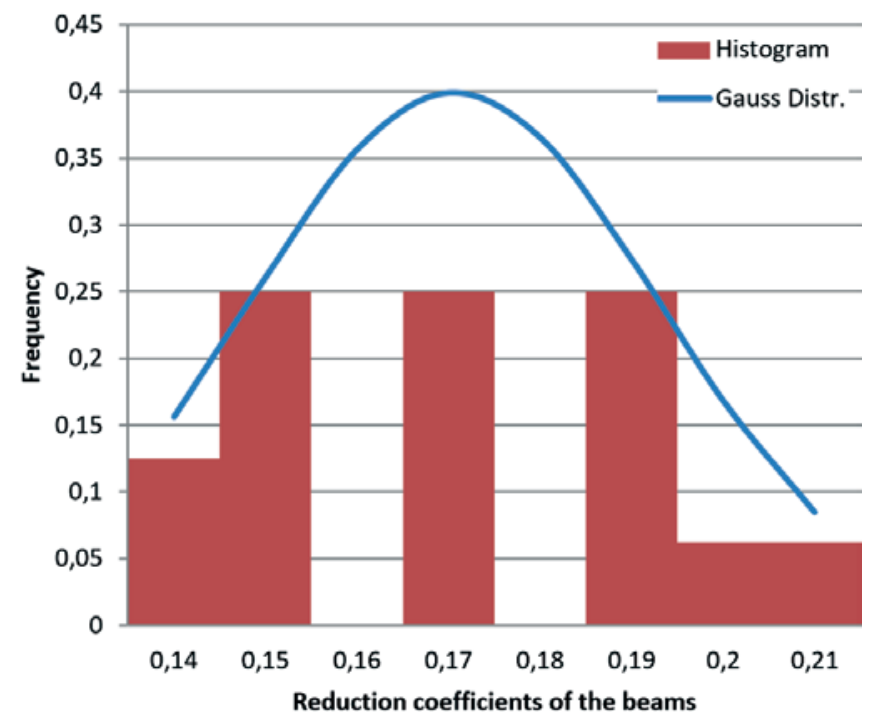

\section{Figure 8}

Gauss distribution graph $\mathrm{x}$ histogram for the beams stiffness in examples with 1 floor Source: Author

\section{Table 11}

Result of statistical analysis for the beams stiffness in examples with 1 floor

\begin{tabular}{|c|c|}
\hline \multicolumn{2}{|c|}{ Descriptive statistics } \\
\hline Average representative & 0,170625 \\
\hline Standard deviation & 0,022351361 \\
\hline Variation coefficient & $13,10 \%$ \\
\hline Number of idealized examples & 16 \\
\hline Minimum value & 0,14 \\
\hline Maximum value & 0,21 \\
\hline Source: Author \\
\hline
\end{tabular}

Table 12

Result of statistical analysis for the beams stiffness in examples with 1 floor

\begin{tabular}{|c|c|}
\hline \multicolumn{2}{|c|}{ Descriptive statistics } \\
\hline Average representative & 0,668125 \\
\hline Standard deviation & 0,043392588 \\
\hline Variation coefficient & $6,49 \%$ \\
\hline Number of idealized examples & 16 \\
\hline Minimum value & 0,62 \\
\hline Maximum value & 0,73 \\
\hline
\end{tabular}

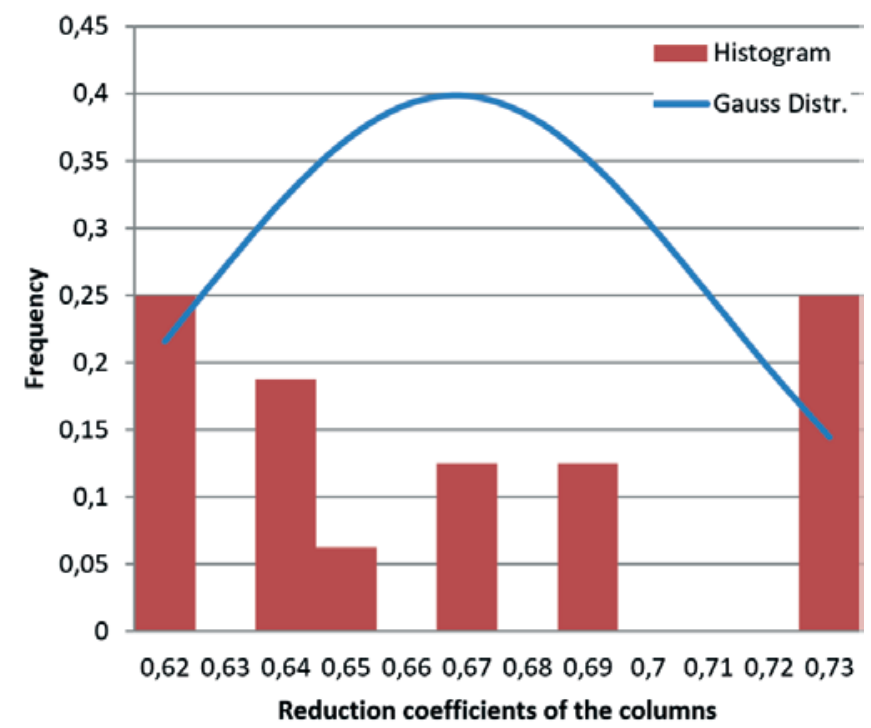

Figure 9

Gauss distribution graph $\mathrm{x}$ histogram for the columns stiffness in examples with 1 floor Source: Author 
Table 13

Proposal for reduction coefficients of stiffness

\begin{tabular}{|c|c|c|}
\hline Floors & $\alpha_{v}$ & $\alpha_{p}$ \\
\hline 1 & 0,17 & 0,66 \\
\hline 2 & 0,15 & 0,71 \\
\hline 3 & 0,14 & 0,72 \\
\hline \multicolumn{3}{|l}{} \\
\hline \multicolumn{2}{|l}{ Source: Author }
\end{tabular}

consideration of the material nonlinearity in the global stability analysis, in buildings with less than four floors.

\subsubsection{Comparison with the work of Bueno (2014)}

In the introduction section we mentioned the researches related to the topic of this study and only the work by Bueno (2014) could be directly compared, as its objective was also to suggest values of stiffness for beams and columns in buildings with less than four floors. Table 14 shows the values of his proposal, where $\gamma_{(z, \mathrm{lim})}=1,3$ is the maximum value of the coefficient $\gamma_{z}$ in the calculation of the second-order global effects.

Initially, it can be indicated that processing 1 and processing 2 of the first iteration, relative to the analysis model of this work (Figure 3 ), correspond to processing 1 and processing 2 of the methodology used by Bueno (2014).

However, from that stage onwards, analysis methodologies differ, because in the model by Bueno (2014), processing 4 consisted of the comparison of values obtained in the geometric nonlinearity evaluation of processing 4 and processing 2 , by means of the equation $\gamma_{z}^{2} \leq 1,10 \cdot \gamma_{z}^{4}$. Moreover, only the analyzed examples that would comply with this relationship were validated. Particularly, Bueno (2014) used the geometric nonlinearity evaluation to verify examples that obtained the best material nonlinearity evaluations so that we could, subsequently, calculate the representative average values of the stiffness reducing coefficients for beams and columns, obtained in each example.

However, in this study, there was no need for comparing the values regarding the geometric nonlinearity, as the "validation" of the coefficients occurs through an iterative process where processing 1 and processing 2 are repeated, adopting for every iteration the coefficients obtained in the previous one. Thus, the iterative process used in the model for this study performs the same function attributed to the conditional equation created by Bueno (2014) and described above.

\section{Table 14}

Reduction coefficients of stiffness of the elements

\begin{tabular}{|c|c|c|c|}
\hline Floors & $\alpha_{v}$ & $\alpha_{p}$ & $\gamma_{(z, l i m)}$ \\
\hline 1 & 0,2 & 0,6 & \\
\cline { 1 - 3 } 2 & 0,3 & 0,6 & \multirow{2}{*}{1,3} \\
\hline 3 & 0,3 & 0,7 & \\
\hline 4 a 10 & 0,4 & 0,8 & \\
\hline \multicolumn{2}{|l}{ Source: Bueno (2014) } \\
\hline
\end{tabular}

Hence, the objective of the employed model is to turn the quantification of values into a considerably effective one, by isolating the analysis only in relation to the bending stiffness reducers for consideration of the material nonlinearity.

Another relevant factor is that Bueno (2014) designed examples with 3, 4, 5 and 8 floors. As such, the stiffness values available on Table 14, for buildings with one and two floors are merely estimations, as no examples were analyzed. On the contrary, in this study, examples have been designed with one, two, and three floors, with the proposal described in Table 13 as the final result.

\section{Conclusions}

This study provides a proposal for the adoption of stiffness reducing coefficients for beams and columns in the approximate consideration of the material nonlinearity $\left(\mathrm{El}_{\mathrm{sec}}=\alpha_{\mathrm{v} / \mathrm{p}} \cdot \mathrm{E}_{\mathrm{ci}} \mathrm{I}_{\mathrm{c}}\right)$ for the analysis of global stability, as follows: buildings with 1 floor $\left(\alpha_{v}=0,17\right.$ and $\left.\alpha_{v}=0,66\right)$, buildings with 2 floors $\left(\alpha_{v}=0,15\right.$ and $\left.\alpha_{v}=0,71\right)$ and buildings with 3 floors $\left(\alpha_{v}=0,14\right.$ and $\left.\alpha_{v}=0,72\right)$.

It could be predicted that the values to be used for buildings with up to three floors were lower than the values suggested by the ABNT NBR 6118:2014, for buildings with, at least, four floors. In fact, in contrast to the results obtained, the values recommended by the standard deserve a re-evaluation, because of the discrepancy between the stiffness value of the beams for buildings with three floors $\left(\alpha_{v}=0,14\right)$ and that suggested by the standard for buildings with four floors or more $\left(\alpha_{v}=0,40\right)$.

Therefore, the suggested values provide a considerably precise evaluation of the approximate consideration of the material nonlinearity in low rise structures, contributing to the analysis of global second-order effects in a safer manner.

\section{Acknowledgments}

The material conditions inherent to the preparation of the research were provided by the State University of Maringá.

The research was funded by the Araucária Foundation/CAPES.

\section{References}

[1] AMERICAN CONCRETE INSTITUTE COMMITTEE 318. Building code requirements for structural concrete and commentary. Farmington Hills, MI, 2014.

[2] BUENO, M. M. E. Study of approximate values of equivalent stiffness for beams and columns for global nonlinear analysis in low rise structures in reinforced concrete. 2014. 238f. Thesis (Doctorate in Structures and Civil Construction) -Brasília University, Brasília, 2014.

[3] BRAZILIAN NATIONAL STANDART ORGANIZATION. NBR 6118: Design of concrete structures - procedure. Rio de Janeiro, 2014.

[4] FRANCO, M. Global and local stability of concrete tall buildings. In: Symposium on space structures, Milan, 1995.

[5] IBRACON. ABNT NBR 6118:2014 Comments and application examples. 1. ed. São Paulo: IBRACON, 2015.

[6] KHUNTIA, M.; GHOSH, S. K. Flexural stiffness of reinforced 
concrete columns and beams: analytical approach. In: ACl Structural Journal. Vol 101, n. 3, p. 351-363, 2004a.

[7] KHUNTIA, M.; GHOSH, S. K. Flexural stiffness of reinforced concrete columns and beams: experimental verification. In: ACI Structural Journal. Vol 101, n. 3, p. 364-374, 2004b.

[8] MARTINS, C. H. Consideration of the material nonlinearity for the reinforced concrete beams, by the refined procedure of NB1. In: Acta Scientiarum, n.1, v. 30, p. 15-18, Maringá, 2008. 